\title{
The computational properties of a simplified cortical column model
}

\author{
Nicholas Cain*, Ram lyer, Christof Koch, Stefan Mihalas \\ From The Twenty Third Annual Computational Neuroscience Meeting: CNS*2014 \\ Québec City, Canada. 26-31 July 2014
}

The mammalian neocortex generally has a repetitious, laminar structure and performs functions integral to higher cognitive processes, including sensory perception, memory, and coordinated motor output. What computations does this circuitry subserve, that might connect these unique structural elements with their biological function? Potjans and Diesmann [1] parameterize a four- layer, two cell-type (i.e excitatory and inhibitory) model of a cortical column. Beginning with their detailed model description, we implement their model using a displacement PDE (DiPDE) population statistic approach. This approach affords fast semianalytic numerical method to solve equations describing homogeneous neuronal populations [2] (see also [3]).

This population statistic approach lends itself to quickly analyzing the response properties of populationscale dynamics of neural tissue. We use this strategy to examine the input-output relationship of the Potjans and Diesmann column model (see also [4]), in an attempt to uncover canonical computations [5] that it might implement. We find that excitatory perturbations to layers 4 (a site of primarily "bottom-up" thalamic input in sensory areas) and 2/3 (a site of primarily "topdown" cortical input) elicit an attenuated, additive perturbation in layer 23 activity, yet offset subtractively in their effect on layer 5 (see Figure 1). This computation might subserve, for example, an inferential update of prior experience with new sensory information. We generalize this finding by computing a linear kernel that describes the response of the column circuit to time varying stimuli.

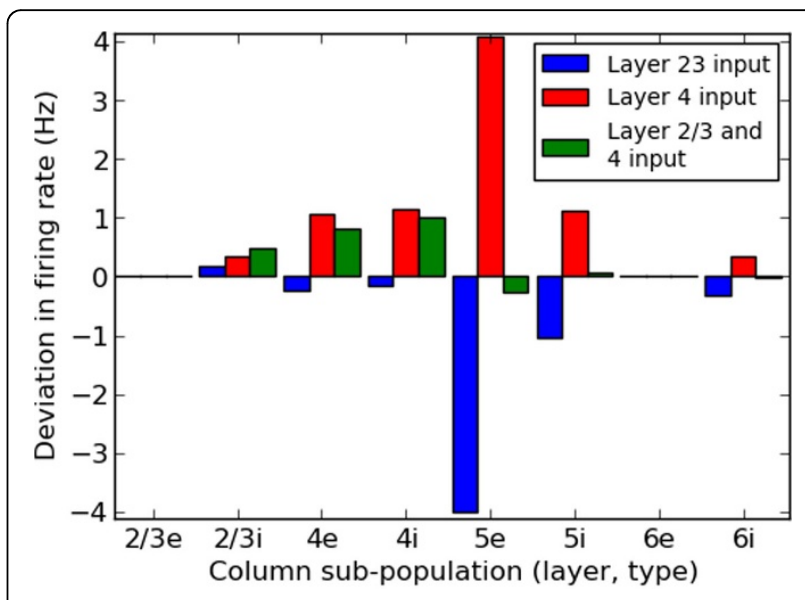

Figure 1 The effect of excitatory perturbations on the firing rate of subpopulations of the cortical column model. Three different excitatory perturbations of $20 \mathrm{~Hz}$ were applied to layers of the model. The first two excited neurons in only layer $2 / 3$, while the third was the sum of the first two. The effect of this third perturbation was additive in the deviation of firing rate of layer $2 / 3$ inhibitory neurons, but subtractive in layer 5 deviation.

\section{Acknowledgements}

This work was funded by the Allen Institute for Brain Science. The authors wish to thank the Allen Institute founders, Paul G. Allen and Jody Allen, for their vision, encouragement, and support.

Published: 21 July 2014

\section{References}

1. Potjans TC, Diesmann M: The Cell-Type Specific Cortical Microcircuit: Relating Structure and Activity in a Full-Scale Spiking Network Model. Cerebral Cortex 2014, 24(3):785-806.

2. Iyer R, Menon V, Buice M, Koch C, Mihalas S: The Influence of Synaptic Weight Distri- bution on Neuronal Population Dynamics. PLOS Comput Biol 2013, 9(10):e1003248.

3. Cain $\mathrm{N}$, et al: Simulations of the statistics of firing activity of neuronal populations in the entire mouse brain. Neuroscience Meeting Planner 2013, 488(01), Society for Neuroscience.

4. Wagatsuma N, Potjans T, Diesmann M, Fukai T: Layer-dependent attentional processing by top-down signals in a visual cortical microcircuit model. Frontiers in Computational Neuroscience 2011, 5.

\footnotetext{
* Correspondence: nicain@alleninstitute.org

Allen Institute for Brain Science, Seattle, WA 98103, USA
} 
5. Douglas R, Martin K: Neuronal circuits of the neocortex. Annu. Rev. Neurosci 2004, 27:419-451.

doi:10.1186/1471-2202-15-S1-P92

Cite this article as: Cain et al: The computational properties of a

simplified cortical column model. BMC Neuroscience 2014 15(Suppl 1):P92.

Submit your next manuscript to BioMed Central and take full advantage of:

- Convenient online submission

- Thorough peer review

- No space constraints or color figure charges

- Immediate publication on acceptance

- Inclusion in PubMed, CAS, Scopus and Google Scholar

- Research which is freely available for redistribution

Submit your manuscript at 